\title{
HIJAZI ARCHITECTURAL OBJECT LIBRARY (HAOL)
}

\author{
A. Baik ${ }^{\mathrm{a},}, \mathrm{J}$. Boehm $^{\mathrm{b}}$ \\ ${ }^{a}$ Dept. of Geomatic Engineering, University College London, Gower Street, London, WC1E 6BT \\ UK - Abaik@kau.edu.sa \\ ${ }^{\mathrm{b}}$ Dept. of Geomatic Engineering, University College London, Gower Street, London, WC1E 6BT \\ $\mathrm{UK}-$ \\ j.boehm@ucl.ac.uk
}

\section{Commission II}

KEY WORDS: Historic Jeddah, JHBIM, TIS, Heritage documentation

\begin{abstract}
:
As with many historical buildings around the world, building façades are of special interest; moreover, the details of such windows, stonework, and ornaments give each historic building its individual character. Each object of these buildings must be classified in an architectural object library. Recently, a number of researches have been focusing on this topic in Europe and Canada. From this standpoint, the Hijazi Architectural Objects Library (HAOL) has reproduced Hijazi elements as 3D computer models, which are modelled using a Revit Family (RFA). The HAOL will be dependent on the image survey and point cloud data. The Hijazi Object such as Roshan and Mashrabiyah, become as vocabulary of many Islamic cities in the Hijazi region such as Jeddah in Saudi Arabia, and even for a number of Islamic historic cities such as Istanbul and Cairo. These architectural vocabularies are the main cause of the beauty of these heritage. However, there is a big gap in both the Islamic architectural library and the Hijazi architectural library to provide these unique elements. Besides, both Islamic and Hijazi architecture contains a huge amount of information which has not yet been digitally classified according to period and styles. Due to this issue, this paper will be focusing on developing of Heritage BIM (HBIM) standards and the HAOL library to reduce the cost and the delivering time for heritage and new projects that involve in Hijazi architectural styles. Through this paper, the fundamentals of Hijazi architecture informatics will be provided via developing framework for HBIM models and standards. This framework will provide schema and critical information, for example, classifying the different shapes, models, and forms of structure, construction, and ornamentation of Hijazi architecture in order to digitalize parametric building identity.
\end{abstract}

\section{INTRODUCTION}

\subsection{The architectural characteristics of Hijazi region}

Little is known about this topic, and a survey of this historic district could be useful in presenting how to effectively restore this district. In fact, the historical houses of Jeddah are rich in architectural characteristics, such as the Roshan, Mashrabiyah, Manjur Pattern and Plaster decoration. Moreover, according to Ragette (2003), "these historical houses have remarkable and simple design and architecture that represent a rich heritage, demonstrating how local craftsmen and builders adapted designs to respond to social demands and other environmental factors in earlier periods". As a consequence of this evolution, the old houses designs have a unique pattern, as well as being authentic and functional. Moreover, the uniqueness of pattern takes a turn for the better in reducing humidity and increasing thermal comfort, as the buildings increase cross ventilation (Eleish, 2009).

According to SCTA (2013), the historical houses of Jeddah have to be "understood as an urban unit active in the making of the city", therefore these houses need to be "studied as typomorphological responses to climate, material and socio-spatial practices". By focusing on the Roshan, it can be found that it is the basic and primary urban unit of the historic Jeddah houses. These Roshans had a significant role in the shaping of the urban fabric, which was originally comprised of tightly knit areas integrating commercial, residential functions, and organised around the main market and the social identity of the historical city. Furthermore, SCTA (2013), pointed out, "Through its programmatic, climatic, spatial and visual characteristics, it contributed to the shaping of the urban morphology, land use patterns and the overall character of Jeddah". In recent years, the historical houses have been used as multi-purpose buildings that house residential and commercial activities.

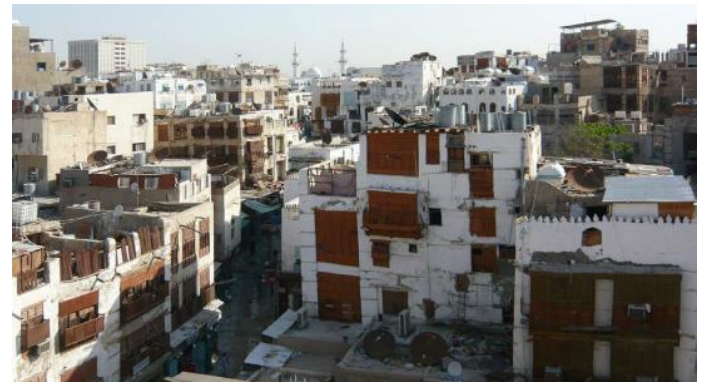

Figure 1. The dense fabric of the old city (Source: SCTA, 2013).

Additionally, at street level, the historical houses are domestic private spaces combined with commercial semi-private spaces such as offices, warehouses and sometimes as hotels during the Hajj (SCTA, 2013). Regarding the climatic considerations, historical Jeddah houses are very effective, which was critical in shaping the morphology and the urban fabric of the historic city. Furthermore, the street network of the historic city corresponds to the prevailing breezes, north and northwest. Lastly; shade and 
light, the alternation of cool and warm surfaces, and hot and cool spaces have an effect on the airflow of the city. The historical houses, in general, could be described as independent or semiindependent units. In such a humid and hot area, this produces more streets and increases air flow and cross ventilation. The proximity of the historical Jeddah houses and their height are also aspects that keep the streets protected from heat and sunrays, and keep it in the shade. In addition, the high houses are used as "wind catchers" in order to allow the sea breeze to maintain continuous vertical air circulation inside the houses, based on the natural upward movement of hot air across stairwells and shafts, pulling air over the windows (Roshan and Mashrabiyah), which in turn cools the inside and favours air circulation. An important architectural solution for dealing with Jeddah's climate is " $\mathrm{Al}$ Mabit in Arabic", which was used for sleeping during the summer nights; it was normally built from panelled wood with louvers and a light roof. Moreover, Al-Lyaly (1990) defines it as, "Al-Mabit on the uppermost floor is like an air pavilion", furthermore, "The louvered timber walls surrounding it on two or sometimes three sides allow the air to circulate freely in the space and at body level thus enhancing the comfort of the occupants". The most common architectural characteristics in historical Jeddah are the Roshan and Mashrabiya, which create a rich and distinct visual character for the old Jeddah city. Further, both Roshan and Mashrabiya play an important part in different ways, such as allowing for cross ventilation, water-cooling, views and decoration, and offering privacy. The next part will explain more about Roshan and Mashrabiya.

\subsection{Roshan and Mashrabiya}

The Roshan and Mashrabiya; which can be described as wooden bay windows, are the most distinctive in the historical Jeddah houses, even though these architectural features are also common in many Islamic cities in the Middle East, such as in Cairo, Baghdad, Damascus, Suakin and Istanbul.

In historic Jeddah, both the Roshan and Mashrabiya are unique, due to many reasons, for instance, the fact that these characteristics are linked from one floor to the other and their sizes are larger and more varied in their carving technique and decoration, with a mixture of influences from Asia and India. The Roshan and Mashrabiya are also found on the ground floor, which is unique to historic Jeddah (SCTA, 2013). Furthermore, due to the diversity of the population and multicultural influences because of visiting artisans and craftsmen, these influences have been reflected in the variations of Roshan and Mashrabiya in historic Jeddah. The owner's tastes and wealth have affected the design of these Roshan and Mashrabiya in quality, size, and decoration.

To analyse the construction of these magnificent characteristics, Roshan and Mashrabiya, it can be noted that they are created with a three-sided wooden structure extending outside of the house's facade. They straddle a supporting base bracket and are covered with a hood that is called "Burnitah" in Arabic. By focusing on the bases of the Roshan and Mashrabiya, it can be observed that the base bracket rests on several stout timbers or cantilever beams embedded deeply into the wall of the facade. These timber beams are hidden by using the decorated brackets and panels, as well as suspended wooden ornaments. The lower section of the Roshan and Mashrabiya are built up using solid panels of wood diagonally positioned in a variety of styles and patterns. The central section of Roshans and Mashrabiyas always contains shutters, often in two rows and the number of these shutters is dependent on the width of the Roshans and Mashrabiyas; the lower row is generally smaller and opens downwards. On the other hand, the larger upper row opens upwards to provide more air circulation and light. Some of the shutters of Roshans and
Mashrabiyas may be opened and closed through sliding up and down in grooves, particularly in low-level Roshans and Mashrabiyas. The top of the Roshan and Mashrabiya are covered with a crown, called "Burnitah" in Arabic; this crown is bigger than the Roshan and Mashrabiya and consists of a wide shadehood or cornice, carrying the crest in the middle. The hood of the crown slopes at an angle from the top to provide shade above the Roshan or Mashrabiya. Moreover, to support the hood, there are additional wooden fringe "stalactites" and side brackets, which also increase the amount of shade provided.

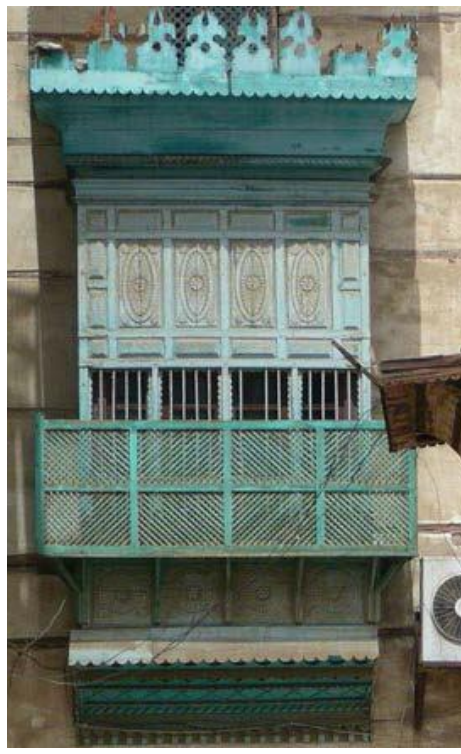

Figure 2. Example of the Roshan.

Roshans and Mashrabiya were built in different styles and sizes. In some houses in Jeddah, the entire façade can be covered with one large Roshan. On the other hand, according to SCTA (2013), "a Roshan may have a regular width, of four or five bays, but extend across two or more levels of the house (multi-storey), or even the full height of the building". Roshan and Mashrabiya, as SCTA (2013) states, "could be linked vertically, by joining the crown of one to the base of the other by wooden bands, or horizontally, by joining the hoods together into one long hood extending over several Roshans and the spaces between them".

Next to the Roshan or Mashrabiya, inside, there is usually a "30 to $50 \mathrm{~cm}$ high" flat platform; this platform was used for seating during the day and for sleeping at night (SCTA, 2013).

\subsection{Manjur pattern}

The Manjur pattern can be described as lattice grilles of wood or a shish net, which are always on the top part of the Roshan or the Mashrabiyah. The main aims of the Manjur are to admit gentle light and to maintain shade, as well as a cool breeze, which is desirable in the hot climate of Jeddah City. From a cultural point of view, the Manjur provides a veil, which permits the families inside the house to look outside without being seen (SCTA, 2013). The concept of the beautiful Manjur designs is to make specially cut laths of wood fit into one another at right angles (criss-crossed) and set within a frame. These Manjur patterns offer a pleasant view from the outside, as well as from the inside. The form in which the sides of the laths are cut determines the form of the resulting open spaces in between, as well as the complete pattern of the Manjur net. According to SCTA (2013), "The shish normally contains two or more shapes arranged in sequences so as to give the Manjur the desired pattern", and generally, the sizes and shapes of the Manjur patterns are 
"selected in such a way as to provide a balanced combination of shade, delicate light, nice breeze, as well as privacy".

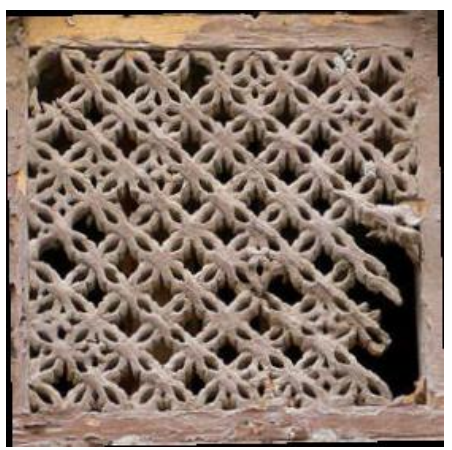

Figure 3. Manjurs in Jeddah houses (Source: SCTA, 2013)

\subsection{Gates and Doors}

Another important architectural characteristic in historic Jeddah are the doors, both external and internal. What is more, these wooden doors, according to SCTA (2013), "have double leaves and are decorated with carved panels representing some of the finest carpentry and decoration in Arabia". The main entrance doors are given considerable attention in the traditional houses of Jeddah city. Regarding the design of these entrance doors, it can be noted that these doors are quite tall, have elaborately decorated panels, carved designs on both sides, and are crowned with carved stone or decorated plasterwork. According to SCTA (2013), these designs "are in the form of repeated floral motifs and rosettes linked by geometrical patterns and/or multi-sided polygons or pointed stars". Also, it can be noted that in some parts of the doors, carving designs are shallow and deeper in others.

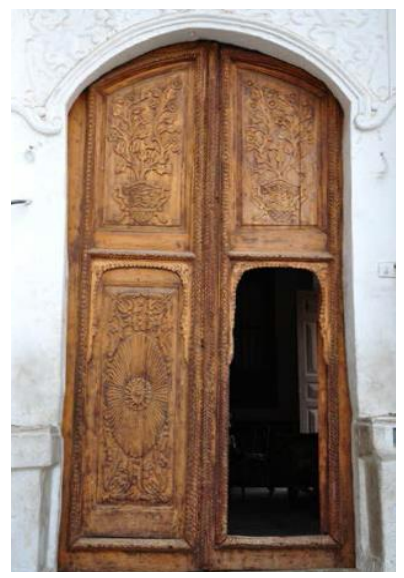

Figure 4. An examples of the wooden doors in Jeddah (Source: SCTA, 2013)

\subsection{Plaster decoration}

Due to the humid and salty weather in Jeddah city, the limestone and coral building blocks have been affected. The main solution for protecting the walls and surfaces of these building has been using plaster. Over time, the plasterer's craft has improved and developed, which has resulted in decorative plaster carvings on the façades. As can be easily observed, the decorative plaster is always centred on the ground level of the façades, particularly around the main windows and main doors of the Jeddah houses. In relation to the process of making the plaster and the decoration, the work was applied to the coral walls when they were still wet. The beauty of the plaster decoration is in the contrast between the engraved and non-engraved surfaces, which create a difference in the shadows and darkness. Great examples of the carved plaster decoration can be found in Jokhdar Historical House and Ribat al-Khonji (SCTA, 2013).

According to SCTA (2013), "Though there is no scientific study devoted to the plaster decorative patterns in Historic Jeddah, and the Gate to Makkah, it appears that older decorations were simpler and more geometric, while later carved plasters became more elaborated with complex floral decorations cut deeper in the plaster though remaining within its thickness".

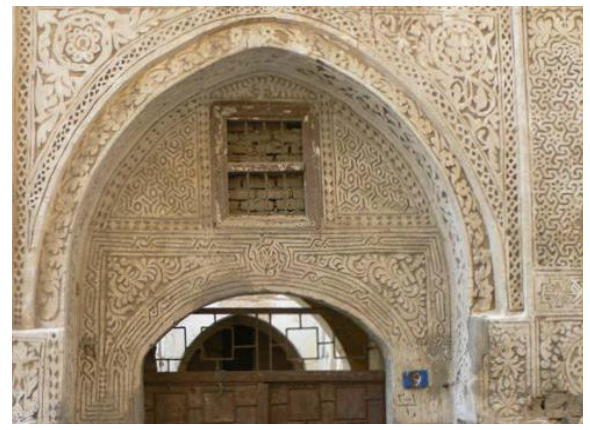

Figure 5: Decorated doorways (Source: SCTA, 2013).

An interesting aspect that has been found in some main façades of the buildings in historic Jeddah is the sgraffito. The sgraffito has always been on the corner of the ground level of two façades and this sgraffito is created by scratching through a surface to reveal a lower layer of contrasting colour. These sgraffito are usually in rectangular or square panels; on the other hand, they rarely come in frieze patterns such as on the Nasif Historical House.

\section{HIJAZI ARCHITECTURAL OBJECTS LIBRARY (HAOL)}

As with many historical buildings in Europe and around the world, building façades are of special interest; and in Jeddah; moreover, the details of such windows, balconies, stonework and ornaments give each historic building its individual character (Böhm et al., 2007). Therefore, each object of these historical buildings must be classified in an architectural object library. Recently, a number of research studies have been focusing on this topic in Europe and Canada, such as Fai et al., (2013); Murphy (2012) and Oreni et al., (2013).

From this standpoint, the Hijazi Architectural Objects Library "HAOL" has reproduced Hijazi elements as 3-D computer models, which are modelled using a Revit Family (RFA). The HAOL is dependent on the image survey and point cloud data. Moreover, it is recreating some of the past, to conserve or to restore these unique parts of these historical buildings. These Hijazi objects, such as Roshan and Mashrabiyah, have become the vocabulary of the Old Jeddah buildings. On the other hand, there is a huge gap in the Hijazi architectural library in providing these unique elements. Due to this issue, the Hijazi architectural objects library has been created for this research. Besides, the object library of JHBIM is connected to the data that was collected from the database, where each single modification of a parameter can lead to a change in the shape of the object. As a result, considering the detail level is very important and how the object models can be simplified in order to suit the preservation plan, as well as being linked to the real opportunities provided by the ability to modify the parameters of the architectonic elements' shapes, in particular, as Historic Jeddah's historical building objects are always unrivalled and irregular. According to Dore and Murphy (2013), "Due to the individuation of the form, grammar and stylistic rules can be used to create a library 
of historical elements" and similarly, for Jeddah historical buildings.

The result will lead to both the building of an abacus of local construction objects and also to match the objects' real dimensions with the information derived from any previous architectural drawings. This will make the models detailed according to the real conditions. The concept of this library is to use it as a plug-in for existing BIM software platforms such as Autodesk Revit. The HAOL will be introduced, documented, and will support any future projects in Historic Jeddah.

\section{THE METHOD OF CREATING JHBIM OBJECT LIBRARY}

The theory behind the HAOL originates from modelling these elements in 3-D modelling software, such as Autodesk Revit. The framework for creating the HAOL began with analysing and understanding the architectural rules of these elements. Secondly, understanding the purposes and the level of detail were extremely key in achieving the most suitable quality needed for the model. Thirdly, the Hijazi Architectural objects were classified in relation to a number of criteria such as the shape, the amount of detail and the style of these details. In the beginning, the library was divided into three main types, "i.e. Roshan, Gate and Manjur patterns". Next, these important Hijazi object types were modelled. Through understanding and simplifying these objects and dividing them into main parts and sub-parts, this step allowed for a reduction in the complexity involved.

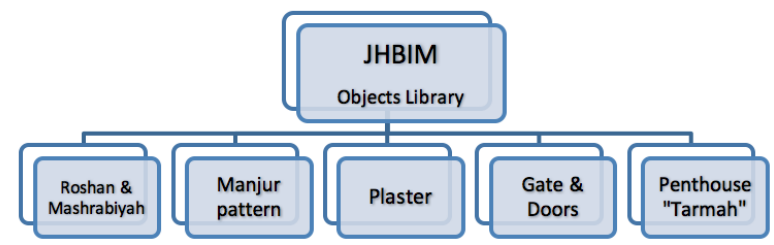

Figure 6. JHBIM objects library layout.

The next step was creating the objects structural form and after that, modelling each single component as close to its real condition as possible, with "as-built level of details". The final step was integrating the multiple data in order to complete the final 3-D model of the Hijazi objects, which was appropriate for exportation to the JHBIM system. There are a number of programs that can be used to build the models of the object library. In this stage, Autodesk Revit (2014, 2015, 2016, and 2017 versions) was used. The Autodesk Revit ${ }^{\circledR}$ software has a lot of advantages, such as rapid building and changes to the 3-D model, high-quality construction documents and a high level of flexibility (Baik et al., 2013). In fact, to deal with such complex Hijazi objects in Autodesk ${ }^{\circledR}$ Revit ${ }^{\circledR}$, the Revit Families must be employed. These files are stored in ". RFA" format and are able to be inserted directly into the Revit project. These RFA files are usually described as data files that hold one or more 3-D models. These 3-D model can be inserted into a 3-D scene and were generated and saved with the Revit Family Editor (ReviverSoft, 2013).

There are two methods for creating Revit family objects. The first method is by using the "Traditional Family Editor". In this method, the object must be sketched onto a 2-D work plan. The second method is by using the "Massing Family". The common stage among the two methods is saving the file in the ". RFA" extension, however, the main difference is that the massing environment is a 3-D work environment, which allows one to work directly in a 3-D view. However, according to Paul Aubin, "the mass category is only useful as a "clay model" or "study model" in the project" (Paul, 2013).

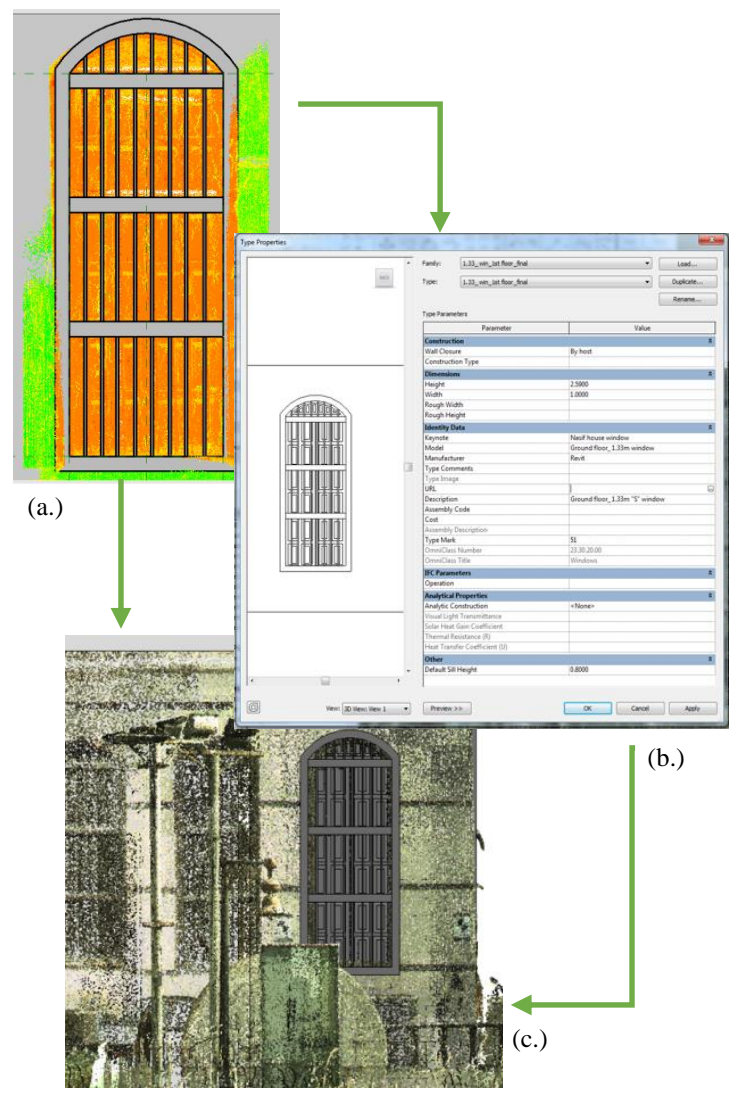

Figure 7: Modelling the window as a Revit family block to be inserted into the Nasif house project. (a.) Modelling the object based on point cloud. (b.) The properties of the object. (c.) Placing the object into the building.

\subsection{Modelling Roshan and Mashrabiyah}

The Roshan and Mashrabiyah can be described as a "large projecting wooden structure" on the Hijazi houses' facades, with a recognisable latticed component. Therefore, it is necessary to give more attention to them. Roshans and Mashrabiyahs are characteristic symbols of the architectural heritage of Jeddah city: they are located almost all over the historic district's buildings. Roshans and Mashrabiyahs cast light and shadow on the houses' façades. These unique elements can always be found on the ground floors. The unit of the Roshan is created by a front and two side boards, and by a ceiling and a floor. The Roshan is created in wood, with mixed moving and fixed parts. The whole Roshan's structure is firmly tied into the brick by a series of wall brackets or consoles. These consoles are made so as to incorporate elaborate and, in some cases, polychrome ornamentation. The under-face contains a part made up of small wooden surfaces, which were designed in "steps". These wooden surfaces are carved and decorated. These parts are laid on top of console underpins, which are inside the brick. The side boards are "stapled" over the opening, utilising metal spikes that are attached to the wooden parts and tied into the wall. In the lower section, the boards are built in grooves, constituting a perfect plinth. Overhead, from the interior, it can be observed that the eye-level is fitted with sliding wooden shutters, full or louvered. These sliding parts slide into the grooves base using a technique known as the guillotine technique. On the higher level, 
Mashrabiyahs parts are fitted to provide air circulation for the room. These structures are surmounted through a wide exquisite cornice. By providing the as built level of detail for both the Roshan and Mashrabiyah, it is possible to protect these Roshan and Mashrabiyah from any further deterioration. Moreover, documenting these Roshan and Mashrabiyah and their components via the most recent digital approaches and the application of the suitable repair methods will ensure longevity of preservation, and conservation of value and authenticity (Adas, 2013). Besides, these important objects can be used to guarantee any future project in the area that can preserve the authenticity of these projects. With regard to modelling the Roshan and Mashrabiyah, it is very important to understand the architectural and structural rules. Through analysing the Roshan and Mashrabiyah, it can be seen that they are shaped via three main parts which are the head, the body and the base. Next, each part is divided into three subtypes, for example, the head was divided into the crown. Next, picked one of the most important Hijazi object types picked, which is the Roshan, and this object was divided into three parts in the library. Each of these parts was then divided into three subtypes. By dividing the elements into subtypes as we did in the case of the Rowshan, we thus reduced the complexity and make it easier to understand. Fourthly, we created the Roshan structures form and modelled each single part as close to its real condition as possible. Finally, after the 3D modelling stage of the main structural and ornamented and complex detailed parts, these multiple data must be integrated in order to complete the final 3D model of the Roshan element, which will be appropriate for exportation to the JHBIM system. Figure 10 shows the steps of Roshan modelling, and these objects will be used as plug-in extensions for existing BIM program platforms, In this case, Autodesk Revit (2014, 2015, 2016, and 2017 versions) has been used.

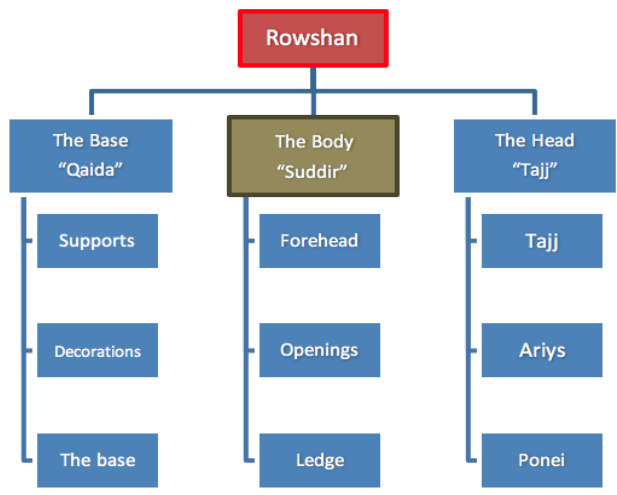

Figure 8. The Roshan parts' layout.

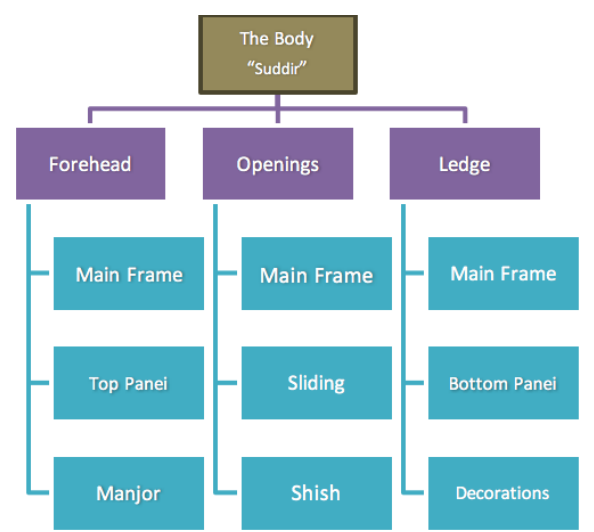

Figure 9. The layout of the body parts of the Roshan.

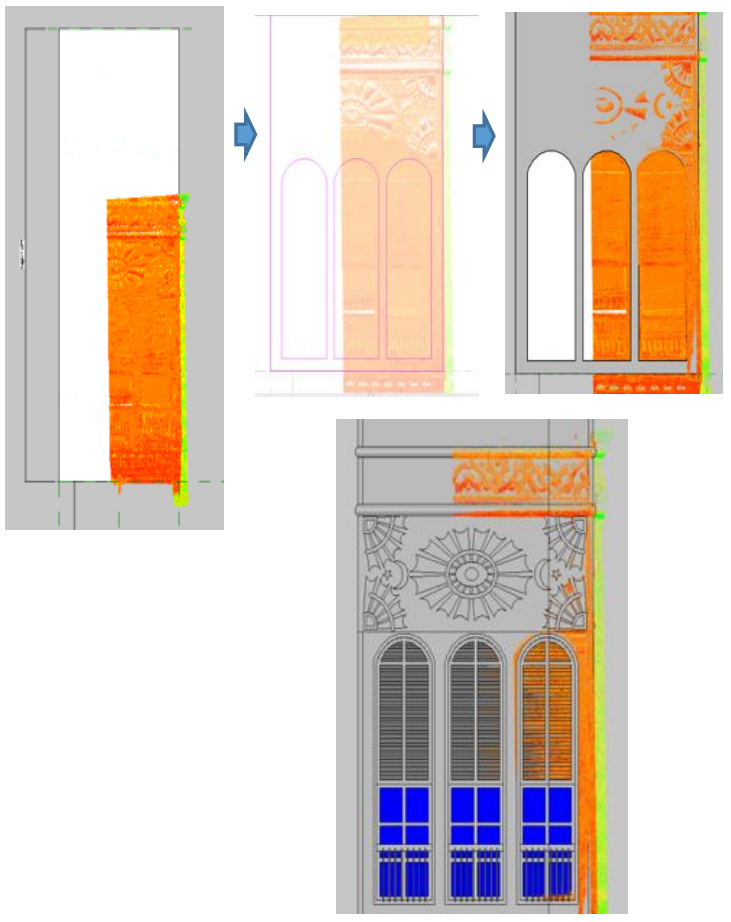

Figure 10. Steps of modelling the main Roshan of Nasif Historical House.

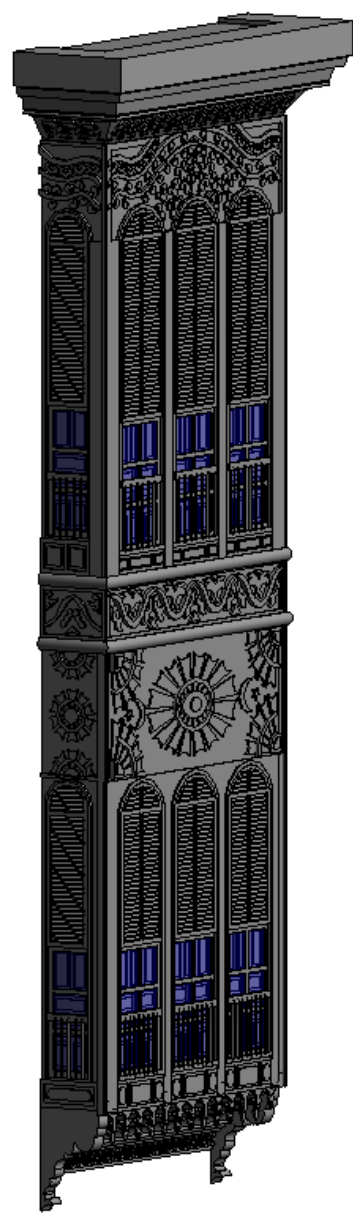

Figure 11. The final result of the 3-D modelling Point into Revit. 


\subsection{Modelling Manjur pattern, wooden shish and woodwork}

The Manjur is one of the most interesting Islamic architectural elements, which can be described as lattice grilles of wood or a shish net. The Manjur pattern is always used to cover the upper section of the Roshan and the doors, and is also used as a fence for the windows. There are different styles of Manjur. However, in Nasif House, there are two or three styles.

The modelling process for the Manjur was based on the laser scanning data. The data was exported in .rcp format and inserted into Autodesk Revit in a separate family file. This step is very important as if this object has been modelled in the same Revit project file, it is impossible for it to be used as a family block in another project.

The second step was understanding the architectural rules of the Manjur. The main concept of the attractive Manjur designs is to make specially cut laths of wood that fit into one another at the right angles (criss-crossed) and set within a frame. These Manjur patterns offer a pleasant view from the outside as well as the inside. The way in which the sides of the laths are cut determines the form of the resulting open spaces in between, as well as the complete pattern of the Manjur net.

The third step is modelling the lath and then duplicating this lath as necessary. Next, modelling the frame is required. Then, arranging the laths in the frame.

Figure 12 shows an example of the modelling steps for the Hijazi architectural object "Manjur example" based on the TLS and Hijazi Architectural pattern book.

(a.)
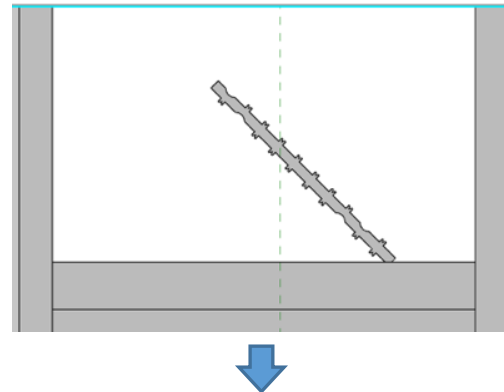

(b.)

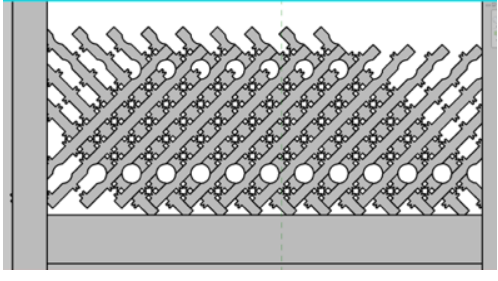

Figure 12. Modelling the Manjur pattern in 3-D. (a.) Modelling the first part of the Manjur. (b.) Combining the Manjur parts. (a.)

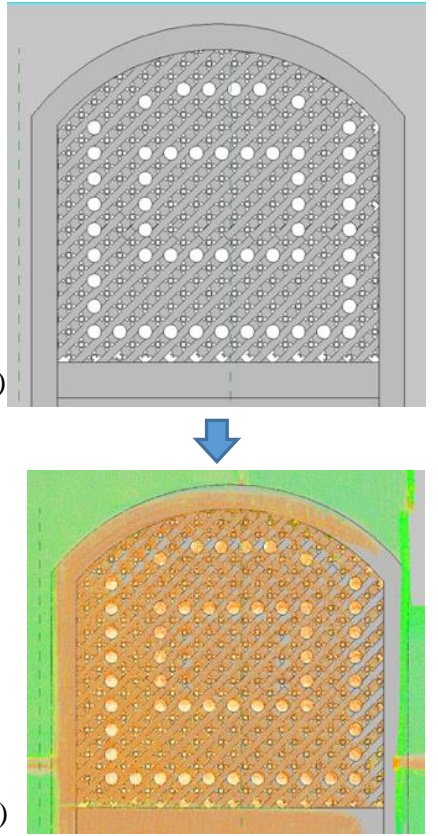

Figure 14. Modelling the Manjur pattern in 3-D. (a.) The final result of the 3-D modelling. (b.) Comparing between the point cloud and the 3-D model of the Manjur.

\subsection{Modelling the plaster decoration works}

Due to the humid and salty weather in Jeddah city, the limestone and coral building blocks have been affected. The main solution for protecting the walls and surfaces of these building is by using plaster. Over time, the plasterer's craft has improved and developed, which has produced decorative plaster carvings on the façades. The plaster decoration works in Historic Jeddah buildings are smaller in comparison to these in the tradition Islamic cities. The common styles in Historic Jeddah are the Quranic verses, floral decorations, and Islamic geometric patterns. This decorative plaster is always on the ground level of the façades, particularly around the main windows and main doors of the Jeddah houses.

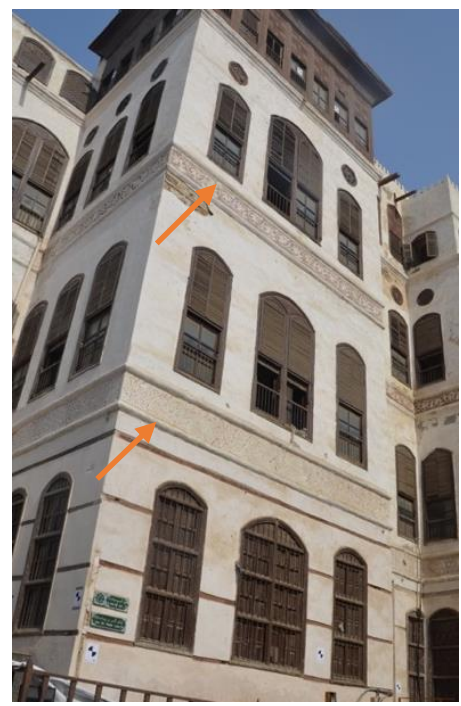

Figure 13. The plaster decoration on the façade of Nasif House. 
Regarding the case study "Nasif Historical House", the style of the plaster decoration is floral decorations. This decorative plaster is concentrated around the main gate of the house and acts as a separator belt between the floors (Figure 13).

Moreover, to model such complicated patterns with many small details, close-range photogrammetry was used alongside the laser scanning. The analysis uncovered a lot of damage to this decorative plaster and therefore sections with less damage were chosen to be modelled.

The next step was to transfer the 3-D point cloud to 3-D (Mesh) surfaces via the MeshLab software. In this step, it is possible to insert them into the Revit model.

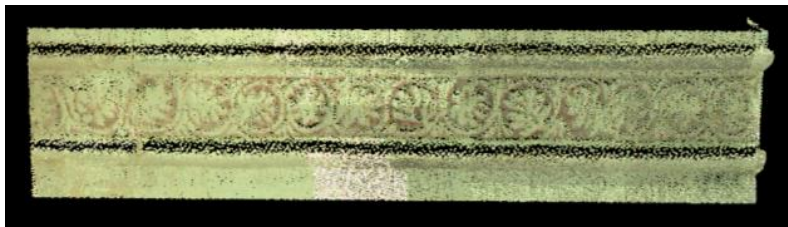

Figure 15. The 3-D plaster point cloud.

\subsection{Modelling the main gate and the doors}

Another important architectural characteristic in historic Jeddah is the main gates and the internal doors. These gates and doors have a unique design with a lot of detail. These gates and doors always have double leaves and are decorated with carved panels representing some of the finest carpentry and decoration in the Hijaz region. Regarding the modelling of the gates and the doors of the case study, the first step was capturing the details of the gates and doors based on the laser scanning and the close-range photogrammetry.

The second step was to export the laser scanning point cloud to (.rcp) format to be modelled in Autodesk Revit as a family block. The third step was to insert the modelled gate and door into the Nasif house Revit project.
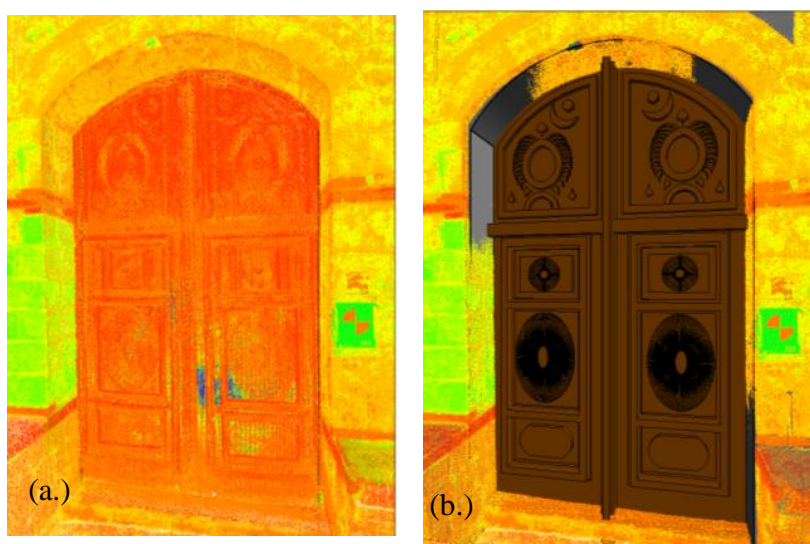

Figure 16. Modelling the main gates of Nasif House.

\section{THE MODELLING RESULT}

in Figure 17. Nasif Historical House JHBIM model after the rendering in Autodesk Revit 2017.

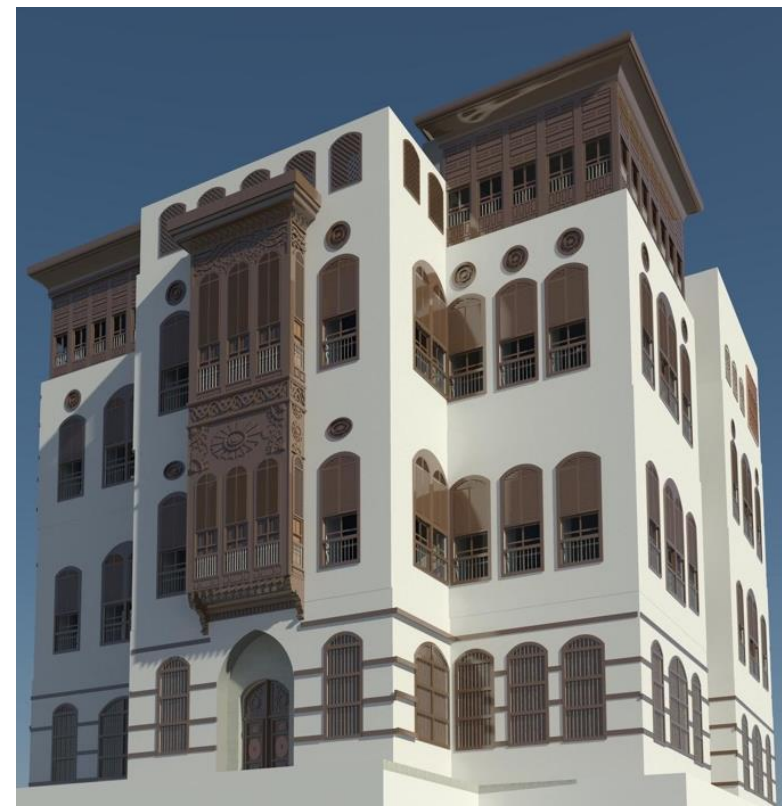

Figure 17. Nasif Historical House JHBIM model after the rendering in Autodesk Revit 2017.

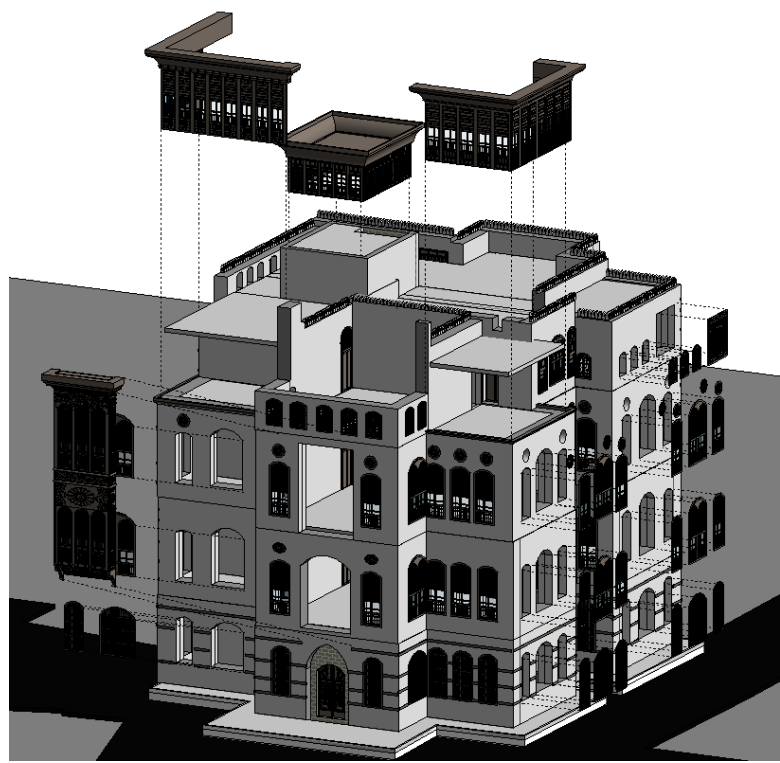

Figure 18. Inserting the HAOL into the JHBIM model of Nasif Historical House. 


\section{JHBIM MODELLING TIME SCALE}

During the first case study of the JHBIM project which was presented in (Baik et al., 2013), the time modelling was too long; around six months. This was due to no digital architectural elements library being available in order to build the Heritage BIM model. Besides, creating the architectural elements of the pilot case study took a lot of time to be modelled. This issue was effected by the schedule of building the Jeddah Heritage BIM model of Radwan House (the pilot case study).

In the main case study of this thesis, through employing the Hijazi Architectural Objects Library (HAOL) as a plug-in Autodesk Revit family to the JHBIM model of Nasif Historical House (the case study), the use of this technique facilitated and sped up the process of creating the model.

The process of modelling the case study of Nasif Historical House took six weeks rather than six months as the pilot case study did.

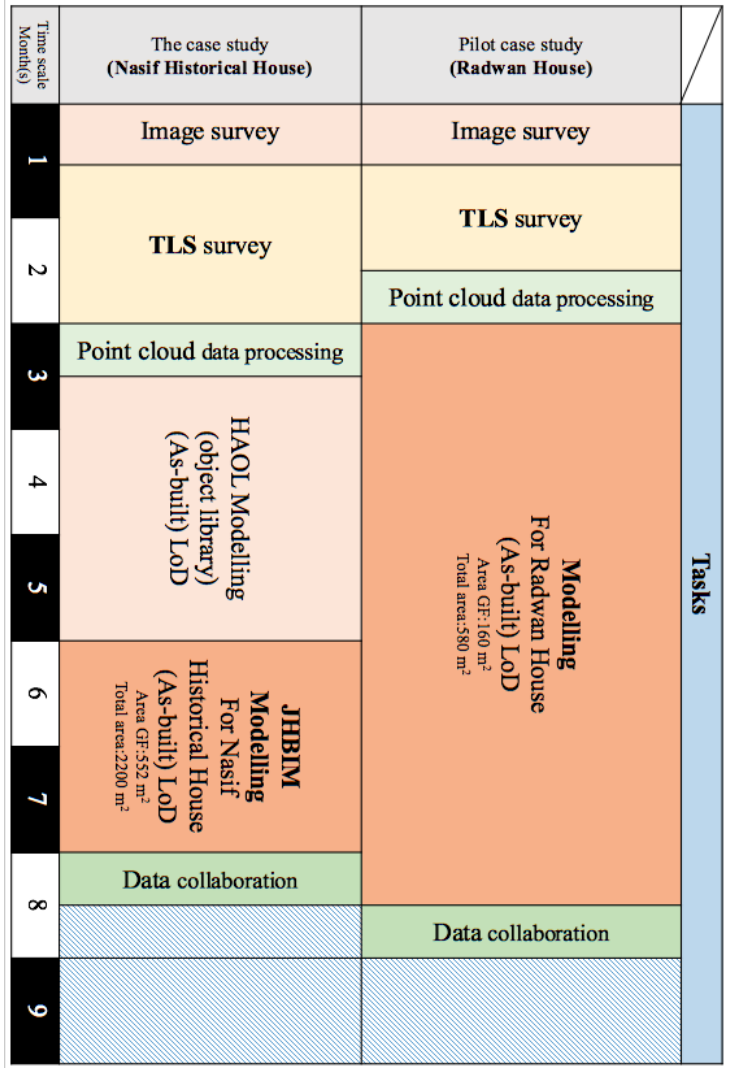

Table 1. The time scale of the JHBIM modelling for the case study and the pilot case study.

\section{THE CONCLUION}

This paper focused on the developing of the HAOL to reduce the cost and the delivering time for heritage and new projects that involve in Hijazi architectural styles. Through this paper, the fundamentals of Hijazi architecture informatics were provided via developing framework for HBIM models and standards. This framework was providing schema and critical information, for example, classifying the different shapes, models, and forms of structure, construction, and ornamentation of Hijazi architecture in order to digitalize parametric building identity. The Hijazi Architectural objects were classified in relation to a number of criteria such as the shape, the amount of detail and the style of these details. In the beginning, the library was divided into three main types, "i.e. Roshan, Gate and Manjur patterns". Afterward, these Hijazi object types were modelled to be used as a plug-in for existing BIM software platforms such as Autodesk Revit. The HAOL introduced, and documented these heritage elements, which will support any future projects in Historic Jeddah, and similar heritage cities in the Hijazi region.

\subsection{Acknowledgement}

I honestly be grateful to the Almighty Allah "God" for seeing myself within this point of my life and I hope that Allah continues to guide and to direct me to the right. Besides, I hope that this work be useful for expert and any involved person in the field of heritage.

\section{REFERENCES}

References from Journals:

Adas, A.A., 2013. Wooden Bay Window (Rowshan) Conservation in Saudi-Hejazi Heritage Buildings. ISPRS-Int. Arch. Photogramm. Remote Sens. Spat. Inf. Sci. 1, 7-11.

Baik, A., Boehm, J., Robson, S., 2013. Jeddah Historical Building Information Modelling "JHBIM" Old Jeddah -Saudi Arabia.

Böhm, J., Haala, N., Becker, S., 2007. Façade modelling for historical architecture, in: XXI International CIPA Symposium. pp. 1-6.

Dore, C., Murphy, M., 2013. Semi-automatic modelling of building facades with shape grammars using historic building information modelling. ISPRS Int. Arch. Photogramm. Remote Sens. Spat. Inf. Sci. 40, 5.

Eleish, A., 2009. Heritage Conservation in Saudi Arabia. Proc. Jt. Int. Symp. IAPS-CSBE Hous. Netw. Revital. Built Environ. Re-Qualif. Old Places New Uses.

Fai, S., Filippi, M., Paliaga, S., 2013. Parametric modelling (BIM) for the documentation of vernacular construction methods: a BIM model for the commissariat building, Ottawa, Canada, in: International CIPA Symposium, Vol. II-5/W1, Strasbourg, France, 2-6 September 2013.

Murphy, M., 2012. Historic Building Information Modelling (HBIM) For Recording and Documenting Classical Architecture in Dublin 1700 to 1830 (Doctor of Philosophy thesis). Trinity College Dublin, Dublin.

Oreni, D., Brumana, R., Cuca, B., Georgopoulos, A., 2013. HBIM for conservation and management of built heritage: Towards a library of vaults and wooden bean floors, in: CIPA 2013XXV International Symposium, ISPRS Annals. pp. 1-6.

Paul, A., 2013. Renaissance Revit: Creating Classical Architecture with Modern Software, 1B edition. ed. CreateSpace Independent Publishing Platform, USA.

SCTA, 2013. HISTORIC JEDDAH, THE GATE TO MAKKAH. SAUDI COMMISSION FOR TOURISM AND ANTIQUITIES, Saudi Arabia, Jeddah.

\section{References from Books:}

Al-Lyaly, S.M.Z., 1990. The traditional house of Jeddah: a study of the interaction between climate, form and living patterns. University of Edinburgh.

Ragette, F., 2003. Traditional domestic architecture of the Arab Region. Edition Axel Menges.

\section{References from websites:}

ReviverSoft, 2013. .rfa File Extension [WWW Document]. URL http://www.reviversoft.com/file-extensions/rfa (accessed 5.25.16). 